\title{
Trends on Major Actinides from an Integral Data Assimilation
}

\author{
Gerald Rimpault ${ }^{1, * *}$, Virginie Huy ${ }^{1,2}$, Gilles Noguère ${ }^{1}$ \\ ${ }^{1}$ CEA, DEN, DER, SPRC, Cadarache, F-13108 St Paul-Lez-Durance, France \\ ${ }^{2}$ Aix Marseille University, Doctoral school 352
}

\begin{abstract}
Nuclear data evaluations on major actinides can be improved by integral data assimilation. Appropriate integral measurements with reliable experimental techniques have been selected such as ICSBEP, IRPhE and MASURCA critical masses, PROFIL irradiation experiments and the FCAIX experimental programme (critical masses and spectral indices). Highly reliable analyses are possible with the use of as-built geometries calculated with the TRIPOLI4 Monte Carlo code. The C/E values have been used in an integral data assimilation solving the Bayes equation. The trends on the JEFF3.1.1 ${ }^{235} \mathrm{U}$ capture cross section are quite consistent with recent differential measurements. Assimilation results suggest up to a $2.5 \%$ decrease for ${ }^{238} \mathrm{U}$ capture from $3 \mathrm{keV}$ to $60 \mathrm{keV}$, and a $4-5 \%$ decrease for ${ }^{238} \mathrm{U}$ inelastic in the plateau region. For this energy range, uncertainties are respectively reduced from $3-4$ to $1-2 \%$ and from $6-9 \%$ to $2-2.5 \%$ for $238 \mathrm{U}$ capture and ${ }^{238} \mathrm{U}$ inelastic. Results on ${ }^{239} \mathrm{Pu}$ fission cross sections are included in posterior uncertainties. The increase trends on ${ }^{239} \mathrm{Pu}$ capture cross-section is of around $3 \%$ in the $[2 \mathrm{keV}-100 \mathrm{keV}]$ energy range. For ${ }^{240} \mathrm{Pu}$ capture cross section, the increase is of around $4 \%$ in the $[3 \mathrm{keV}-100 \mathrm{keV}]$ energy range and goes in the same direction as a recent evaluation.
\end{abstract}

\section{INTRODUCTION}

Five out the six Generation IV concepts are Fast Reactors with breeding capability (they produce $\mathrm{Pu}$ out of depleted Uranium) and with ability to use possibility $\mathrm{Pu}$ and MA, that would otherwise be a waste (Pu from PWR-MOX not suitable for PWR).

In France, 2006 June 28 act requires the design of a generation of sodium fast reactors, those being the most mature Generation IV concept. It is the reason for which CEA with its industrial partners started the design of ASTRID ${ }^{1,2}$ (Advanced Sodium Technological Reactor for Industrial Demonstration), a $600 \mathrm{MWe}$ sodium-cooled fast reactor concept. Its construction should demonstrate the feasibility of a SFR design with enhanced safety and its ability to achieve a zero breeding gain hence enabling to use the entire Uranium ore and not only ${ }^{235} \mathrm{U}$.

\footnotetext{
*Corresponding author : gerald.rimpault@cea.fr
} 
Sodium Fast Reactors require the development and validation of scientific calculation tools as a proof of their characteristics used in their safety dossiers. Nuclear data, the input parameters of the neutronic codes, constitute the main source of uncertainty in neutronic calculations ${ }^{3}$. For instance, uncertainty (in pcm) on critical mass for the ASTRID core (using JEFF3.1.1 and its associated COMAC-V1 nuclear data covariances) amounts up to 1558 pcm. Major actinides are contributing significantly to this uncertainty as Table 1 illustrates.

Table 1. Uncertainty breakdown (in pcm) on critical mass for the ASTRID core (using COMAC-V1 nuclear data covariances).

\begin{tabular}{|l|c|c|c|c|c|c|c|c|}
\hline Isotope & Fission & Capture & Elastic & Inelastic & NxN & Nu & $\begin{array}{l}\text { Fission } \\
\text { Spectrum }\end{array}$ & Total \\
\hline${ }^{16} \mathrm{O}$ & 0 & 110 & 50 & 0 & 0 & 0 & 0 & 120 \\
\hline${ }^{23} \mathrm{Na}$ & 0 & 20 & 10 & 10 & 0 & 0 & 0 & 30 \\
\hline${ }^{56} \mathrm{Fe}$ & 0 & 80 & 30 & 50 & 0 & 0 & 0 & 100 \\
\hline${ }^{238} \mathrm{U}$ & 439 & 869 & 30 & 649 & 30 & 70 & 60 & 1168 \\
\hline${ }^{238} \mathrm{Pu}$ & 10 & 20 & 0 & 0 & 0 & 80 & 40 & 100 \\
\hline${ }^{239} \mathrm{Pu}$ & 699 & 190 & 10 & 60 & 10 & 100 & 210 & 759 \\
\hline${ }^{240} \mathrm{Pu}$ & 669 & 300 & 0 & 60 & 10 & 20 & 170 & 619 \\
\hline${ }^{241} \mathrm{Pu}$ & 70 & 90 & 0 & 10 & 0 & 70 & 150 & 200 \\
\hline${ }^{242} \mathrm{Pu}$ & 40 & 50 & 0 & 20 & 0 & 20 & 40 & 80 \\
\hline TOTAL & 1069 & 859 & 60 & 649 & 30 & 170 & 320 & 1558 \\
\hline
\end{tabular}

Existing fertile blankets with depleted $U$ induces great sensitivities to ${ }^{238} \mathrm{U}$ cross-sections, notably inelastic. The use MOx fuel with Pu retrieved from PWR-MOx spent fuel induces high sensitivities not only to ${ }^{239} \mathrm{Pu}$ cross sections but also to other $\mathrm{Pu}$ isotopes cross sections (notably ${ }^{240} \mathrm{Pu}$ ).

\section{STRATEGY USED}

Integral Data Assimilation (IDA) can contribute to nuclear data improvement if attention is being given to ways that minimize the possibility of creating compensating errors. This approach has been done in the past and it is important to learn from past integral data assimilation works to develop a strategy that can avoid important compensating errors.

\subsection{Previous integral data assimilation works}

Since the early seventies, several integral experiments assimilation work for fast reactor applications have been conducted.

Among them, the statistical adjustment method (called BARACCA) was used to produce two CARNAVAL libraries (III and IV) ${ }^{4}$ with the objectives of answering needs for PHENIX and SUPER-PHENIX respectively. For the adjustment, for each nuclear data, equiprobable probabilities were associated to an interval of possible values. This choice was done because assuming that the discrepancy in $\mathrm{C} / \mathrm{E}$ values for integral experiments came mainly from normalization issues when performing microscopic measurements. Because, there were no constraints in the a priori multigroup cross sections other than the boundary of the initial interval, work resulted in compensating errors between ${ }^{238} \mathrm{U}$ capture cross sections and ${ }^{239} \mathrm{Pu}$ fission cross section.

ERALIB $1^{5}$ is a library resulting from an integral data adjustment whose experimental database includes 355 integral data (critical masses, spectral indices, buckling etc.) coming from 71 distinct experimental programs. Prior variances-covariances matrices associated to 
nuclear data were produced from expert judgements. The improvements made on the assimilation process include:

- The use of Gaussian distributions for multigroup nuclear data to perform adjustments based on Bayes Inference using Generalized Least Square Methods.

- The use of statistical indicators ( $\chi^{2}$ criteria) to identify inconsistent integral data, which need to be eliminated from the experimental database.

However, the experimental database included many unreliable measurements and some of covariance were lacking physical meaning (especially for ${ }^{23} \mathrm{Na}$ ). This led in particular to discrepant sodium void worth.

\subsection{Current Strategy}

To avoid deficiencies identified in previous Integral Data Assimilation (IDA) work, a more reliable nuclear data library was used JEFF3.1.16 for all isotopes with the exception of ${ }^{23} \mathrm{Na}$ for which JEFF3.2 was used ${ }^{7}$. The associated COMAC V1 covariance ${ }^{8}$ were used as they mimic the evaluation process itself.

Only reliable integral experiments have been selected. They are ICSBEP, IRPhE and MASURCA critical masses, PROFIL irradiation experiments and the FCA-IX experimental programme (critical masses and spectral indices). Highly reliable experiment analyses are now possible avoiding method approximation and using as-built geometries as it is possible with the TRIPOLI4 Monte Carlo code 9 .

Marginalization technique has been used for light and structural isotopes for which approximations (anisotropy, secondary neutron energy distribution) in the integral data assimilation technique are rather high. A test on whether Prompt Fission Neutron Spectrum (PFNS) needs to be fitted or not (such as in ERALIB1). It appears from this test that PFNS is a major source of uncertainty and requires to be fitted ${ }^{12}$.

Attention has been given to ways that minimize compensating errors. Compensating errors between ${ }^{238} \mathrm{U}$ capture and ${ }^{239} \mathrm{Pu}$ fission (such as in CARNAVAL IV) has been eliminated by using first only $\mathrm{U}$-fueled experiments then adding Pu-fueled experiments.

The IDA has been using Bayesian inference ${ }^{10}$ with a minimization of a cost function (1) in which $M_{\sigma}$ is the covariance matrix associated to nuclear data and $M_{E}$ the one associated to integral experiments.

$$
\chi_{G L S}^{2}=\left(\boldsymbol{\sigma}-\boldsymbol{\sigma}_{\text {a priori }}\right)^{T} M_{\sigma}^{-1}\left(\boldsymbol{\sigma}-\boldsymbol{\sigma}_{\text {a priori }}\right)+(E-C(\boldsymbol{\sigma}))^{T} M_{E}^{-1}(E-C(\boldsymbol{\sigma}))
$$

Solutions for nuclear data are given by equation (2) where $S$ is the sensitivity matrix calculated with the ERANOS code system ${ }^{11}$ while associated uncertainties are given by equation (3):

$$
\begin{aligned}
& \boldsymbol{\sigma}^{\prime}-\boldsymbol{\sigma}_{\text {a priori }}=M_{\sigma} \cdot S^{T}\left(M_{E}+S \cdot M_{\sigma} \cdot S^{T}\right)^{-1} \cdot\left(\boldsymbol{E}-C\left(\boldsymbol{\sigma}_{\text {a priori }}\right)\right) \\
& M^{\prime}{ }_{\boldsymbol{\sigma}}=M_{\sigma}-M_{\sigma} \cdot S^{T}\left(M_{E}+S \cdot M_{\sigma} \cdot S^{T}\right)^{-1} S \cdot M_{\sigma}
\end{aligned}
$$

\section{INTEGRAL DATA ASSIMILATION STUDIES}

\subsection{Integral experiments}

The Uranium configurations chosen for the exercise are MASURCA R2, MASUSCA 1B, FCA IX-1 to 7, GODIVA and FLATTOP U235. The Plutonium configurations chosen are MASURCA 1A', MASURCA ZONA2, ZPPR10A, ZPR6/7, ZPR6/7 high Pu240, BFS 82-2, MASURCA PRE-RACINE 2A \& 2B, SNEAK 7A \& 7B, JEZEBEL Pu239 \& Pu240, FLATTOP Pu239. Also, FCA-IX fission chambers C/Es of Np237, Am241, Am243, Pu238, $\mathrm{Pu} 242, \mathrm{Cm} 244$ have been used as well as PHENIX PROFIL irradiated samples C/E on U238, $\mathrm{Pu} 238, \mathrm{Pu} 239, \mathrm{Pu} 240, \mathrm{Pu} 241, \mathrm{Pu} 242$, Am241, Np237. C/E values display a great dispersion 
in results. Nuclear data uncertainties (of the order of 1000 to $2000 \mathrm{pcm}$ ) are far beyond experimental uncertainties, which justify the use of IDA method.

\subsection{Trends for ${ }^{235} \mathrm{U}$ Capture}

As seen on Figure 1, the trends were a -27 to $-33 \%$ decrease at $1-2 \mathrm{keV}$ (end of RRR) which is in agreement with Danon measurements $(2017)^{13}$ and a +8 to $+10 \%$ increase in the $10-100 \mathrm{keV}$ region (URR) which is in agreement with Jandel measurements (2012) ${ }^{14}$. Uncertainties are significantly reduced.

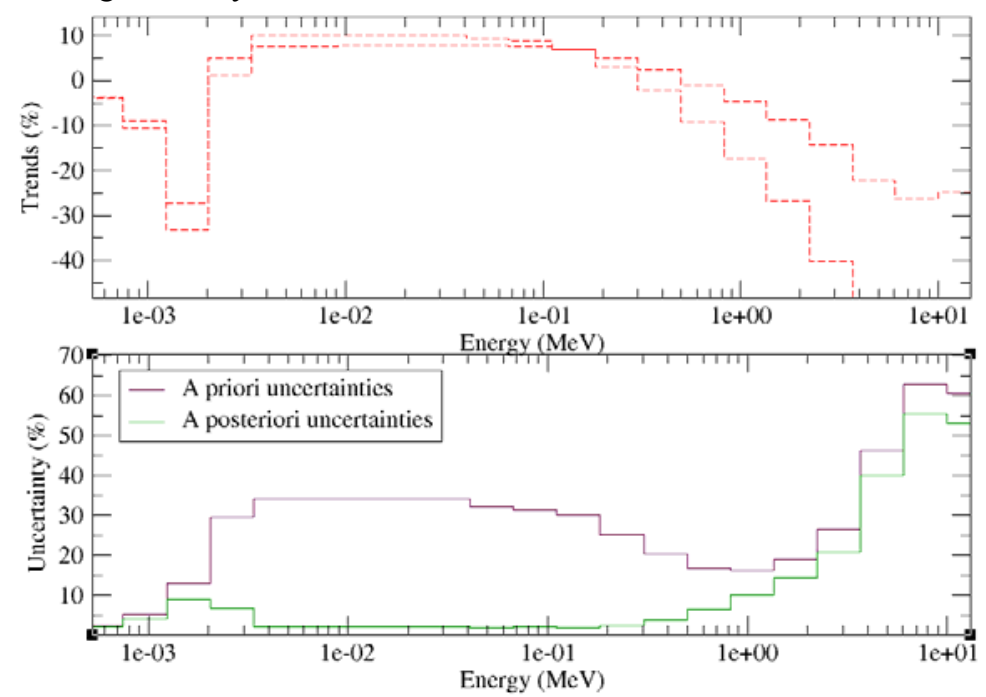

Figure 1: Trends on ${ }^{235} \mathrm{U}$ capture

The consistency of integral data assimilation results on ${ }^{235} \mathrm{U}$ capture cross section with recent differential measurements encourages us to rely on the simultaneous use of PROFIL $\mathrm{C} / \mathrm{E}$ and various U235 enriched critical masses to reassess capture cross sections.

\subsection{Trends for ${ }^{238} \mathrm{U}$ Capture and Inelastic}

For ${ }^{238} \mathrm{U}$ inelastic and capture cross sections, a comparison of ${ }^{235} \mathrm{U}^{238} \mathrm{U}$ assimilation results and U-Pu assimilation results allows us to conclude that the trends proposed for these cross sections are not the result of compensating errors with $\mathrm{Pu}$ nuclear data. Assimilation results suggest up to a $2.5 \%$ decrease for ${ }^{238} \mathrm{U}$ capture from $3 \mathrm{keV}$ to $60 \mathrm{keV}$, and a $4-5 \%$ decrease for ${ }^{238} \mathrm{U}$ inelastic in the plateau region. For these energy range, uncertainties are respectively reduced from $3-4$ to $1-2 \%$ and from $6-9 \%$ to $2-2.5 \%$ for ${ }^{238} \mathrm{U}$ capture and ${ }^{238} \mathrm{U}$ inelastic. The simultaneous use of GODIVA and FLATTOP-235U and JEZEBEL 239Pu and FLATTOP-239Pu is relevant to reassess ${ }^{238} \mathrm{U}$ inelastic cross sections. Their critical mass $\mathrm{C} / \mathrm{E}$ are greatly affected by the reflecting properties of the FLATTOP core depleted Uranium blankets very sensitive to this cross section.

Assimilation results for ${ }^{238} \mathrm{U}$ capture are compared with differential measurements ${ }^{15}$ and with the "a priori" JEFF-3.1.1, CIELO and JEFF-3.3 evaluation (Figure 2). Posterior uncertainties for assimilation results are in dotted line. 


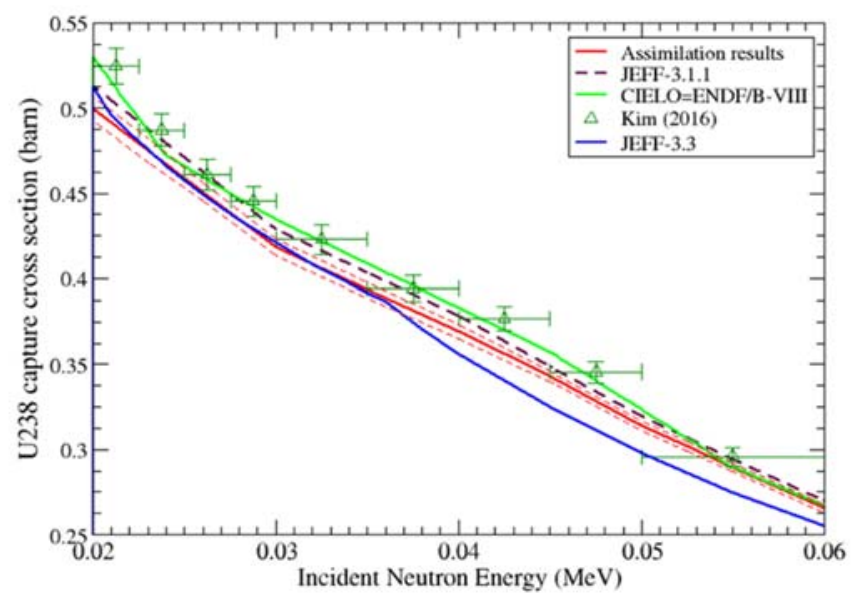

Figure 2: Assimilation Results compared to major evaluations for ${ }^{238} \mathrm{U}$ capture

Because Prompt Fission Neutron Spectrum (PFNS) lacks some differential measurements, variances are large. Since integral experiments available cannot distinguish between $v$ and $\chi$ (PFNS) the possibility of having compensating errors is high. Hence, a parametric study has been conducted with ${ }^{235} \mathrm{U}$ and ${ }^{238} \mathrm{U}$ PFNS fitted or not through assimilation. The magnitude of trends on ${ }^{238} \mathrm{U}$ capture cross sections differ on whether ${ }^{235} \mathrm{U}$ and ${ }^{238} \mathrm{U}$ PFNS is fitted or not through assimilation.

In the plateau region $(\sim 1 \mathrm{MeV}$ to $6 \mathrm{MeV})$, a $5-6 \%$ decrease is suggested for ${ }^{238} \mathrm{U}$ inelastic. This decrease trend is in agreement with recent evaluations (see suggested value compared to CIELO and JEFF-3.3 ones on Figure 3; Posterior uncertainties for assimilation results are in dotted line).

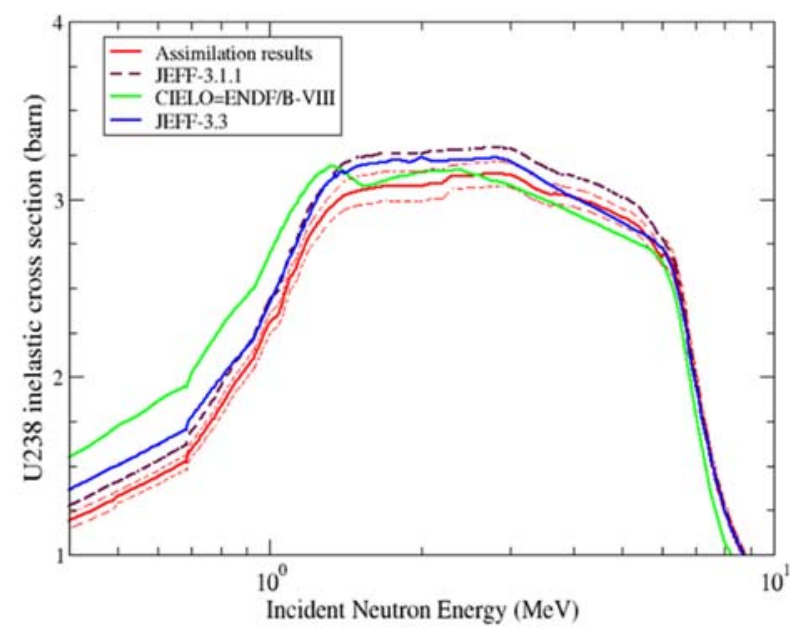

Figure 3: Assimilation Results compared to major evaluations for ${ }^{238} \mathrm{U}$ inelastic 
Notably, the simultaneous use of FLATTOP-U235/GODIVA and FLATTOPPu239/JEZEBEL enables us to discriminate contributions from U238 and fissile isotopes. Indeed, GODIVA is a bare U235 sphere while FLATTOP-U235 is surrounded by a $\mathrm{U}_{\text {depleted }}$ blanket. The same occurs for JEZEBEL and FLATTOP-Pu.

\subsection{Trends for $\mathrm{Pu}$ isotopes}

Summary of trends on $\mathrm{Pu}$ isotope data, which can have a significant impact for the ASTRID core, are given in Table 2.

Table 2. Trends on $\mathrm{Pu}$ isotope cross sections

\begin{tabular}{|c|c|c|c|c|}
\hline $\begin{array}{l}\text { Cross } \\
\text { section }\end{array}$ & Trends (\%) & Energy range & Experiments & Comments \\
\hline $\begin{array}{l}{ }^{239} \mathrm{Pu} \\
\text { fission }\end{array}$ & $<1 \%(+/-1.7 \%$ or less) & $0.1 \mathrm{keV}-500 \mathrm{keV}$ & $\begin{array}{c}\text { Pu-fueled critical } \\
\text { masses }\end{array}$ & $\begin{array}{l}\text { Trends included in } \\
\text { posterior unc. }\end{array}$ \\
\hline $\begin{array}{l}{ }^{239} \mathrm{Pu} \\
\text { capture }\end{array}$ & from -1.4 to $-4.8 \%$ (+/- $2-5 \%)$ & $0.04 \mathrm{keV}-300 \mathrm{keV}$ & $\begin{array}{c}\text { PROFIL and critical } \\
\text { masses }\end{array}$ & \\
\hline \multirow[b]{2}{*}{$\begin{array}{l}{ }^{240} \mathrm{Pu} \\
\text { fission }\end{array}$} & from -7.5 to $-9.6 \%(+/-8-11 \%)$ & $0.75 \mathrm{keV}-100 \mathrm{keV}$ & \multirow[b]{2}{*}{ Mostly JEZEBEL- ${ }^{240} \mathrm{Pu}$} & \multirow{2}{*}{$\begin{array}{l}\text { Risk of compensating } \\
\text { errors with multiplicity } \\
\text { and PFNS. Trends are } \\
\text { close to posterior } \\
\text { uncertainties. }\end{array}$} \\
\hline & from -3.5 to $-4.6 \%(+/-4-7 \%)$ & $1 \mathrm{keV}-3.7 \mathrm{MeV}$ & & \\
\hline $\begin{array}{l}{ }^{240} \mathrm{Pu} \\
\text { capture }\end{array}$ & from 2.5 to $-4.2 \%(+/-2-4.5 \%)$ & $0.7 \mathrm{keV}-100 \mathrm{keV}$ & PROFIL & \\
\hline $\begin{array}{l}{ }^{242} \mathrm{Pu} \\
\text { fission }\end{array}$ & $-10 \%(+/-3.5 \%)$ & $500 \mathrm{keV}-4 \mathrm{MeV}$ & FCA-IX IS & $\begin{array}{l}\text { Underestimated prior } \\
\text { uncertainties ( } 2 \% \text { in } \\
\text { the plateau region) }\end{array}$ \\
\hline \multirow{2}{*}{$\begin{array}{l}{ }^{242} \mathrm{Pu} \\
\text { capture }\end{array}$} & from -3 to $-9 \%(+/-2-5 \%)$ & $3 \mathrm{keV}-300 \mathrm{keV}$ & \multirow{2}{*}{$\begin{array}{l}\text { Trends are driven by } \\
\text { PROFIL (C/E 1.14). }\end{array}$} & \multirow{2}{*}{$\begin{array}{l}\text { IDA trends have an } \\
\text { unreliable energy } \\
\text { breakdown due to } \\
\text { Covariances }\end{array}$} \\
\hline & around $-20 \%(+/-12 \%)$ & $0.4 \mathrm{keV}-3 \mathrm{keV}$ & & \\
\hline
\end{tabular}

Results on ${ }^{239} \mathrm{Pu}$ fission cross sections are included in posterior uncertainties which have been significantly reduced through the IDA process (from $3.5-2 \%$ to $2.5-0.5 \%$ ) . There is no differential measurement able to reach that type of uncertainty. This means that IDA process will be needed in a way or another. The increase trends on ${ }^{239} \mathrm{Pu}$ capture cross-section is of around $3 \%$ in the [2 keV-100 keV] energy range. From $4 \mathrm{keV}$ up to $30 \mathrm{keV}$, the ENDF/BVIII evaluation corresponds to JEFF-3.1.1. For ${ }^{240} \mathrm{Pu}$ capture cross section, the increase is of around $4 \%$ in the $[3 \mathrm{keV}-100 \mathrm{keV}]$ energy range and goes in the same direction as the recent ENDF/B.VIII evaluation though at a much lower level.

\section{IMPACT ON THE ASTRID CFV CORE}

There is a significant impact of ${ }^{238} \mathrm{U}$ capture and inelastic on the critical mass of the ASTRID core but also ${ }^{239} \mathrm{Pu},{ }^{240} \mathrm{Pu}$ and ${ }^{242} \mathrm{Pu}$ fission cross-sections. With a prior value for the critical mass of 1.02688 (1.02908 with JEFF-3.1.1 for all isotopes except ${ }^{23} \mathrm{Na}$ for which JEFF3.2 is used: Impact of using ${ }^{23} \mathrm{Na}$ evaluation from JEFF-3.2 instead of JEFF-3.1.1 on the ASTRID core reactivity: $-220 \mathrm{pcm}$.) the IDA conducted led to a posterior value of 1.02255 $(-435 \mathrm{pcm})$. The Integral Data Assimilation reduces uncertainties associated to nuclear data significantly with, in particular, a significant reduction on ${ }^{239} \mathrm{Pu}$ and ${ }^{240} \mathrm{Pu}$ fission crosssections. 
Table 3. Impact of the nuclear data trends (in pcm) on the critical mass of the ASTRID core and associated uncertainty (a priori uncertainties using COMAC-V1 nuclear data covariance are also given).

\begin{tabular}{|c|c|c|c|}
\hline all values in $\mathrm{pcm}$ & Impact on $\mathrm{k}_{\mathrm{eff}}$ & $\begin{array}{c}\text { Posterior } \\
\text { associated } \\
\text { uncertainty } \\
\text { contribution }\end{array}$ & $\begin{array}{c}\text { Prior } \\
\text { associated } \\
\text { uncertainty } \\
\text { contribution }\end{array}$ \\
\hline U238_CAPTURE & 249 & 180 & 869 \\
\hline U238_NU & 0 & 40 & 70 \\
\hline U238_FISSION_SPECTRUM & 12 & 40 & 60 \\
\hline U238_ELASTIC & -7 & 30 & 30 \\
\hline U238_INELASTIC & 342 & 60 & 649 \\
\hline Pu238_CAPTURE & 6 & 10 & 20 \\
\hline Pu238_FISSION & -82 & 20 & 10 \\
\hline PU239_CAPTURE & -96 & 20 & 190 \\
\hline Pu239_FISSION & -143 & 120 & 699 \\
\hline Pu239_NU & -49 & 40 & 100 \\
\hline PU239_FISSION_SPECTRUM & -37 & 50 & 210 \\
\hline PU240_CAPTURE & -100 & 40 & 300 \\
\hline Pu240_FISSION & -323 & 170 & 669 \\
\hline Pu240_NU & -2 & 10 & 20 \\
\hline PU240_FISSION_SPECTRUM & -66 & 90 & 170 \\
\hline Pu241_CAPTURE & 7 & 70 & 90 \\
\hline Pu241_FISSION & -8 & 60 & 70 \\
\hline Pu241_NU & -6 & 60 & 70 \\
\hline PU241_FISSION_SPECTRUM & -29 & 130 & 150 \\
\hline Pu242_CAPTURE & 99 & 30 & 50 \\
\hline Pu242_FISSION & -197 & 20 & 40 \\
\hline Total actinides $(\mathrm{pcm})$ & -435 & 490 & 1558 \\
\hline
\end{tabular}

\section{CONCLUSION AND PERSPECTIVES}

Integral Data Assimilation (IDA) in this work has proved to be efficient in identifying the sources of possible normalization problems in the differential measurements. This achievement is mainly due to the progresses in identifying the different sources of uncertainties whether they are from nuclear data evaluations themselves (through covariance) or from integral experiments (either for their set up or their modelling).

The trends on the JEFF3.1.1 ${ }^{235} \mathrm{U}$ capture cross section are quite consistent with recent differential measurements.

IDA results suggest also a $2.5 \%$ decrease for ${ }^{238} \mathrm{U}$ capture from $3 \mathrm{keV}$ to $60 \mathrm{keV}$, and a 4$5 \%$ decrease for ${ }^{238} \mathrm{U}$ inelastic in the plateau region. For this energy range, uncertainties are respectively reduced from $3-4$ to $1-2 \%$ and from $6-9 \%$ to $2-2.5 \%$ for ${ }^{238} \mathrm{U}$ capture and ${ }^{238} \mathrm{U}$ inelastic.

The increase trend on ${ }^{239} \mathrm{Pu}$ capture cross section is of around $3 \%$ in the $[2 \mathrm{keV}-100 \mathrm{keV}]$ energy range. For ${ }^{240} \mathrm{Pu}$ capture cross section, the increase is of around $4 \%$ in the $[3 \mathrm{keV}-100$ $\mathrm{keV}$ ] energy range and goes in the same direction as the recent ENDF/B.VIII evaluation though at a much lower level.

As perspectives for future works, there is a need of more differential measurements and more reliable nuclear data covariance.

For instance, IDA has identified the lack of differential measurements, in particular for prompt fission neutron spectrum or ${ }^{238} \mathrm{U}$ inelastic and parametric studies have shown that 
nuclear data covariance data with better reliability are required (for PFNS and some capture cross sections).

There is also a request to have covariance associated to anisotropy of scattering and distribution of secondary energy neutrons in particular for light and structural isotopes. This will enable to improve the IDA by incorporating all sources of uncertainties. Also adding more integral experiments will help increasing the reliability of the IDA, specifically if these are defined to target a given spectrum or nuclide.

\section{References}

1. M. Saez, J.-C. Robin, B. Riou, A. Villedieu, D. Deprest, and G. Prele, "Status of ASTRID nuclear island pre-conceptual design," Fast Reactor and Related Fuel Cycles FR13 Proc. Int. Conf., 2015.

2. F. Varaine et al., "Pre-conceptual design study of ASTRID core," 2012 International Congress on Advances in Nuclear Power Plants (ICAPP '12), Chicago, IL, June 24-28, 2012

3. G. Rimpault, "Nuclear Data Needs for the Assessment of Generation IV Nuclear Energy Systems",", International Workshop on Nuclear Data Needs for Generation IV Nuclear Energy Systems, Antwerpen 5-7 April 2005

4. J. P. Chaudat, "The CARNAVAL 4 adjusted library," Trans Am Nucl. Soc., vol. 27, no. 877, 1977.

5. E. Fort, W. Assal, G. Rimpault, J. Rowlands, P. Smith, and R. Soule, "Improved performances of the fast reactor calculational system ERANOS-ERALIB1 due to improved a priori nuclear data and consideration of additional specific integral data," Ann. Nucl. Energy Oxf., vol. 30, no. 18, pp. 1879-1898, 2003.

6. A. Santamarina, D. Bernard et al., "The JEFF-3.1.1 Nuclear Data Library. Validation results from JEF-2.2 to JEFF-3.1.1," JEFF Report 22, OECD/NEA Data Bank 2009.

7. P. Archier, "Contribution à l'amélioration des données nucléaires neutroniques du sodium pour le calcul des réacteurs de génération IV," Grenoble Alpes, 2011.

8. P. Archier et al., "CONRAD Evaluation Code: Development Status and Perspectives," Nucl. Data Sheets, vol. 118, pp. 488-490, Apr. 2014.

9. E. Brun et al., 'TRIPOLI-4®, CEA, EDF and AREVA reference Monte Carlo code', Ann. Nucl. Energy, vol. 82, pp. 151-160, Aug. 2015.

10. T. Bayes, "An Essay Toward Solving a Problem in the Doctrine of Chances," Philos. Trans. R. Soc. Lond., vol. 53, pp. 370-418, 1763.

11. G. Rimpault et al, "The ERANOS Code and Data System for Fast Reactor Neutronic Analyses, International Conference on the New Frontiers of Nuclear Technology : Reactor Physics, Safety and High-Performance Computing", PHYSOR'02, October 710, 2002, Seoul, Korea.

12. L. Berge, "Contribution à la modélisation des spectres de neutrons prompts de fission. Propagation d'incertitudes sur un calcul de fluence cuve," Grenoble Alpes, 2015.

13. Y. Danon et al. Simultaneous Measurement of ${ }^{235} U$ Fission and Capture Cross Sections From $0.01 \mathrm{eV}$ to $3 \mathrm{keV}$ Using a Gamma Multiplicity Detector. Nuclear Science and Engineering, vol. 187, 291-301, 2017.

14. M. Jandel et al. New Precision Measurements of the ${ }^{235} \mathrm{U}(\mathrm{n} ; \gamma)$ Cross Section: Physical Review Letters; 109(20); November 2012:

15. H. I. Kim et al., Neutron capture cross section measurements for ${ }^{238} U$ in the resonance region at GELINA, Phys:J:A; 52(6) : 170; June 2016: 